\title{
108. Stimulation of Melanogenesis in Melanoma Cells Growing in Serum-Free Medium by Fetal Bovine Serum and Dimethylsulfoxide
}

\author{
By Kunio Iwata and Naomichi INUI \\ Section of Cell Biology and Cytogenetics, Biological Research \\ Center, The Japan Tobacco and Salt Public Corporation \\ (Communicated by Sajiro Makino, M. J. A., Nov. 12, 1980)
}

Melanoma cells possess a unique ability of melanogenesis which is stimulated in vitro by various substances, such as cyclic adenosine monophosphate (Kreider et al., 1973), theophylline (Kreider et al., 1975) and melanocyte stimulating hormone (Wong et al., 1973). Most in vitro studies of these cells have, however, been made in medium which contained serum. Since serum involves many factors with unknown biological effects, and then results obtained from such experiments do not provide clear-cut information.

Recently, we reported the establishment of two melanoma cell lines in a serum-free chemically defined medium (Iwata and Inui, 1980). They seem to be useful for analysis of the mechanism of melanogenesis, since, in serum-free media, stimulating factors should act directly on cells without interacting with serum components.

The present paper describes some stimulatory effects of fetal bovine serum (FBS) and dimethylsulfoxide (DMSO) on melanogenic activities of melanoma cells cultured in serum-free medium.

Materials and methods. G4F clone cells, derived from B16 mouse melanoma cells, were cultured in the serum-free medium for over 30 passages. Details of the method for culture of the cells in serum-free, chemically defined medium were described previously (Iwata and Inui, 1980).

For stimulation of melanin synthesis and tyrosinase activity of the cells, 1 to $2 \times 10^{5}$ and 6 to $8 \times 10^{5}$ cells were inoculated into $60 \mathrm{~mm}$ and $90 \mathrm{~mm}$ plastic dishes (Falcon Plastic, U.S.A.), respectively. The cells were treated with FBS (Flow Lab., Australia) or DMSO (Sigma Chem., U.S.A.) two days after inoculation. After cultivation with FBS or DMSO for various periods, the cells were harvested by treatment with $0.25 \%$ trypsin (Difco Lab., U.S.A.) plus $0.02 \%$ ethylenediaminetetraacetic acid disodium salt in $\mathrm{Ca}^{++}$and $\mathrm{Mg}^{++}$free Hanks' solution. The cells were washed once with Hanks' solution and then

Address: Biological Research Center, The Japan Tobacco and Salt Public Corporation, 23 Nakogi, Hatano, Kanagawa 257, Japan. 
with $0.25 \mathrm{M}$ sucrose in 1/15 M Sörensen phosphate buffer ( $\mathrm{pH}$ 6.8). Cell pellets were stocked at $-20^{\circ} \mathrm{C}$ for measurement of their melanin content and tyrosinase activity. Melanin was measured by the method of Whittaker (1963) and was expressed as the optical density (OD) at $400 \mathrm{~nm}$ per $10^{6}$ cells. For determination of tyrosinase (EC, 1.14. 18.1) activity on cells, the stocked cells were suspended in 1 to $3 \mathrm{ml}$ of $0.5 \%$ sodium deoxycholate in $0.001 \mathrm{~N} \mathrm{NaOH}$ and homogenized. The homogenate was centrifuged at $30,000 \mathrm{rpm}$ for $20 \mathrm{~min}$ in a Hitachi $65 \mathrm{P}$ ultracentrifuge, and then tyrosinase activity in the supernatants was rapidly measured. The activity was measured colorimetrically as dope oxidase by a modification of the method previously reported (Iwata and Takeuchi, 1977), and was expressed as $\Delta E$ / $\mathrm{min} / 10^{6}$ cells.

Results. The effects of FBS on the cell number and melanin content of G4F clone cells are summarized in Table I. The cell number increased with a high concentration of FBS, while melanin synthesis of the cells was enhanced slightly by $1 \%$ FBS and greatly by $10 \%$ FBS.

Table I. Effects of FBS on cell growth and melanin content of melanoma cells in the stationary phase

\begin{tabular}{ccccc}
\hline $\begin{array}{c}\text { FBS } \\
\begin{array}{c}\text { concentration } \\
(\%)\end{array}\end{array}$ & $\begin{array}{c}\text { Cell number } \\
\left(\times 10^{6}\right) / \text { dish }\end{array}$ & $($ S.E. $)$ & $\begin{array}{c}\text { Melanin content } \\
(\text { OD } 400 \mathrm{~nm} / \\
\left.10^{6} \text { cells }\right)\end{array}$ & (S.E.) \\
\hline 0 & 3.61 & $(0.14)$ & 0.0402 & $(0.0014)$ \\
0.1 & 3.75 & $(0.21)$ & 0.0353 & $(0.0025)$ \\
1 & 3.85 & $(0.15)$ & 0.0604 & $(0.0072)$ \\
10 & 4.48 & $(0.07)$ & 0.1675 & $(0.0099)$ \\
\hline
\end{tabular}

$1.5 \times 10^{5}$ cells grown in serum-free medium were inoculated into $60 \mathrm{~mm}$ dishes. Two days later, they were treated with medium containing various concentrations of FBS. The medium was changed every 2 days. After 6-days of treatment the cells were harvested. Values are the averages and standard errors (S.E.) for triplicate dishes.

Table II. Effects of DMSO on cell growth and melanin content of melanoma cells in the stationary phase

\begin{tabular}{ccccc}
\hline $\begin{array}{c}\text { DMSO } \\
\begin{array}{c}\text { concentration } \\
(\%)\end{array}\end{array}$ & $\begin{array}{c}\text { Cell number } \\
\left(\times 10^{6}\right) / \text { dish }\end{array}$ & (S.E.) & $\begin{array}{c}\text { Melanin content } \\
(\text { OD400 nm/ } \\
\left.10^{6} \text { cells }\right)\end{array}$ & (S.E.) \\
\hline 0 & 3.96 & $(0.04)$ & 0.0376 & $(0.0024)$ \\
0.5 & 5.12 & $(0.06)$ & 0.0624 & $(0.0036)$ \\
1 & 4.73 & $(0.10)$ & 0.1515 & $(0.0092)$ \\
\hline
\end{tabular}

$2 \times 10^{5}$ cells grown in serum-free medium were inoculated into $60 \mathrm{~mm}$ dishes. Two days later they were treated with medium containing various concentrations of DMSO. Values are the averages and standard errors (S.E.) for triplicate dishes. 
The effects of DMSO on the cell number and melanin content are shown in Table II. One \% DMSO did not inhibit cell growth, whereas the melanin content of the cells increased with the concentration of DMSO. A large amount of melanin was produced by cells in medium containing $1 \% \mathrm{DMSO}$, the amount being comparable to that of cells in medium with $10 \%$ FBS.

The relationships between cell growth and tyrosinase activity of cells treated with 10\% FBS and 1\% DMSO are shown in Figs. 1 and 2 , respectively. Growth rate of the cells in $10 \%$ FBS was higher than that of cells in serum-free medium. Tyrosinase activity showed an

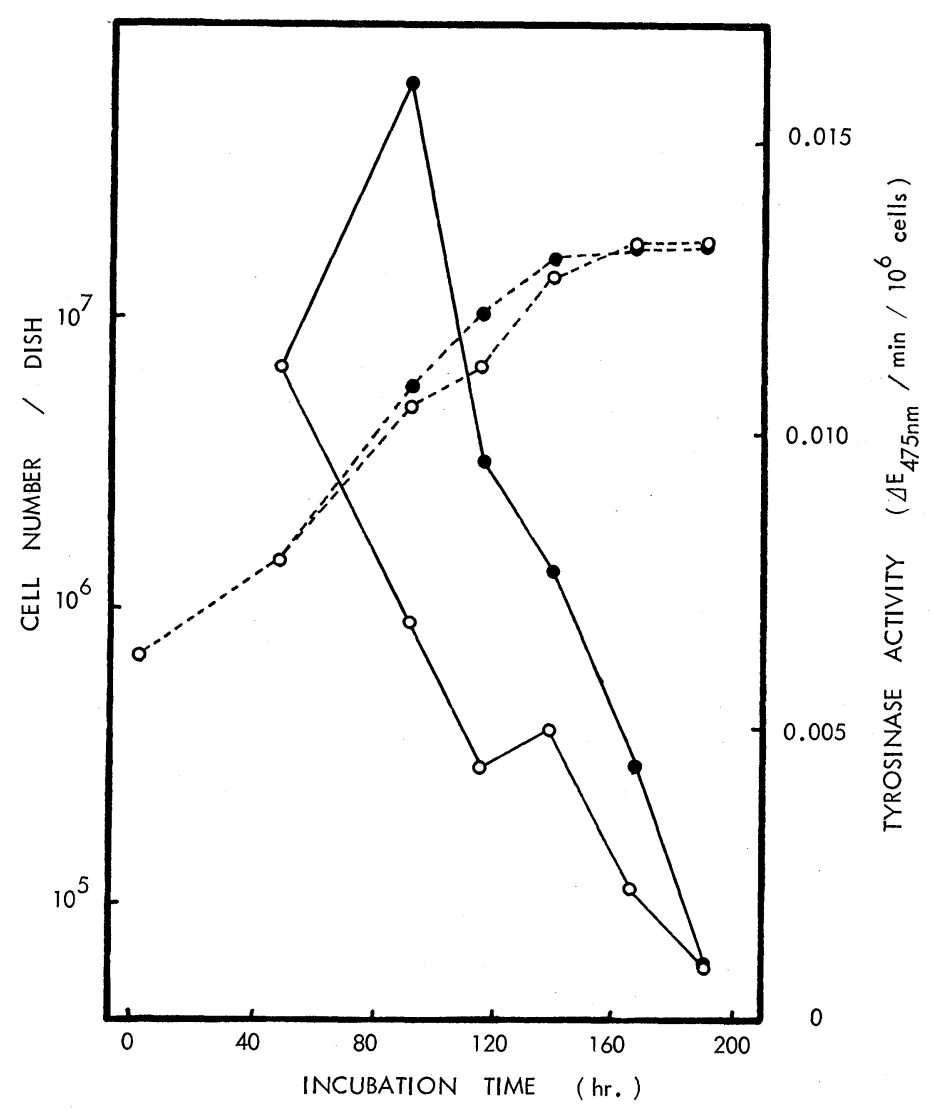

Fig. 1. Effects of $10 \%$ FBS on cell growth and tyrosinase activity of melanoma cells grown in serum-free medium. - - - cell growth; _tyrosinase activity; $\bigcirc$, control; $\bullet, 10 \%$ FBS. $7 \times 10^{5}$ cells grown in serum-free medium were inoculated into $90 \mathrm{~mm}$ dishes at $0 \mathrm{~h}$. Two days. later they were treated with medium with or without $10 \%$ FBS. The: medium was changed every 2 days. Tyrosinase activity was assayed as described in the Materials and methods. Points are the averages for triplicate dishes. 
increase $48 \mathrm{hrs}$ after addition of $10 \% \mathrm{FBS}$, and after reaching a maximum, the activity decreased to the untreated cell level in the stationary phase (Fig. 1). In medium containing $1 \%$ DMSO, the growth rate of the cells was almost the same as that of the control (Fig. 2). The tyrosinase activity increased gradually to a maximum on day 4 and then decreased slightly, but on day 10 it was still about

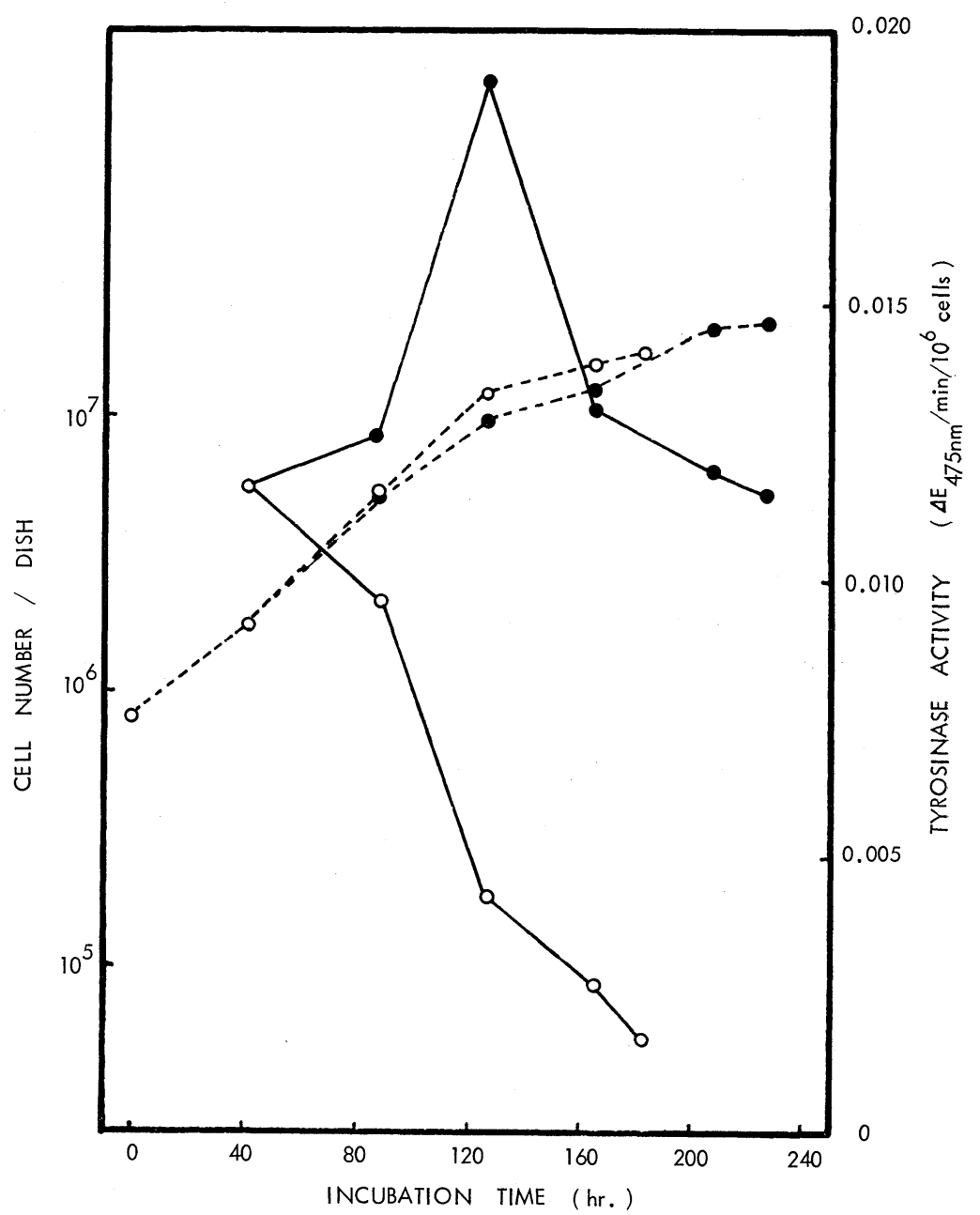

Fig. 2. Effects of 1\% DMSO on cell growth and tyrosinase activity of melanoma cells grown in serum-free medium. ---, cell growth; -, tyrosinase activity; $\bigcirc$, control; $\bullet, 1 \% \mathrm{DMSO} .8 \times 10^{5}$ cells grown in serum-free medium were inoculated into $90 \mathrm{~mm}$ dishes at $0 \mathrm{~h}$. Two days later they were treated with medium with or without $1 \%$ DMSO. The medium was changed every 2 days. Tyrosinase activity was assayed as described in the Materials and methods. Values are the averages for triplicate dishes. 
4 to 5 times that of untreated cells (Fig. 2).

Discussion. The present study resulted in that FBS and DMSO induced a stimulation of melanogenesis in the mouse melanoma cells growing under a serum-free condition without inhibiting cell growth. In the presence of $10 \% \mathrm{FBS}$, the tyrosinase activity increased rapidly, reached a maximum, and then gradually decreased to the same level as in untreated cells in the stationary phase. Evidence presented suggests that the effect of FBS is transitory, if it were to stimulate de novo synthesis of tyrosinase.

DMSO has been known to induce differentiation of cells such as murine erythroleukemia cells (Friend et al., 1971) and neuroblastoma cells (Kimhi et al., 1976). Recently, Huberman et al. (1979) reported that DMSO stimulated melanin synthesis in human melanoma cells. In the present study, melanin synthesis and tyrosinase activity of mouse melanoma cells growing in the serum-free medium were also stimulated by DMSO. The mode of activation of tyrosinase activity by DMSO seems to be different from that by FBS in the following points: First, DMSO required a longer lag period than FBS for stimulation of the enzyme activity. This seems to indicate that more than one cell cycle is necessary for activation of tyrosinase activity by DMSO, similarly to its effect on differentiation in murine erythroleukemia cells (Levenson and Hausman, 1979). Second, the tyrosinase activity of the cells treated with $1 \%$ DMSO, unlike that of FBS-treated cells, remained higher than that of untreated cells in the stationary phase. Evidence was thus provided indicating that the stimulating effect of $1 \%$ DMSO on tyrosinase synthesis persisted for a certain period of time.

Most in vitro studies previously presented have suggested that melanogenesis in melanoma cells induced by chemicals, such as cyclic adenosine monophosphate (Kreider et al., 1973), theophylline (Kreider et al., 1975), melanocyte stimulating hormone (Wong and Pawelek, 1973) and DMSO (Huberman et al., 1979), is accompanied by a reduction of cell growth. In the present study, however, FBS and DMSO stimulated melanogenesis without inhibiting cell growth. Analysis in detail of this phenomenon, especially on the effects of DMSO, has now been in progress in our laboratory.

Acknowledgements. We are very grateful to Dr. Takuji Takeuchi, the Tohoku University, Sendai, for his advice and encouragement throughout this work, and to $\mathrm{Dr}$. Funan $\mathrm{Hu}$, the Oregon Regional Primate Research Center, U.S.A., for kind permission of using B16 mouse melanoma cells. Thanks are due to Emeritus Professor, Dr. Sajiro Makino, M. J.A., for critical reading of the manuscript. 


\section{References}

Friend, C., Scher, W., Holland, J. G., and Sato, T. (1971) : Proc. Natl. Acad. Sci., U.S.A., 68, 378-382.

Huberman, E., Heckman, C., and Langenbach, R. (1979) : Cancer Res., 39, 2618-2624.

Iwata, K., and Takeuchi, T. (1977) : J. Invest. Dermatol., 68, 88-92.

Iwata, K., and Inui, N. (1980) : Proc. Japan Acad., 56B, 146-151.

Kimhi, Y., Palfrey, C., Spector, I., Barak, Y., and Littauer, U. Z. (1976) : Proc. Natl. Acad. Sci., U.S.A., 73, 462-466.

Kreider, J. W., Rosenthal, M., and Lengle, N. (1973) : J. Natl. Cancer Inst., 50, 555-558.

Kreider, J. W., Wade, D. R., Rosenthal, M., and Densley, T. (1975) : J. Natl. Cancer Inst., 54, 1457-1467.

Levenson, R., and Housman, D. (1979) : Cell, 17, 485-490.

Whittaker, J. R. (1963) : Dev. Biol., 8, 99-127.

Wong, G., and Pawelek, J. (1973) : Nature New Biol., 241, 213-215 . 